\title{
EL SISTEMA INTERAMERICANO Y LA PRO- TEC-CIÓN DE LOS DERECHO HUMANOS DE LAS MUJERES: MONITOREO DE LAS PETICIONES CONTRA BRASIL (2006-15)
}

THE INTER-AMERICAN SYSTEM AND THE PROTECTION OF WOMEN'S HUMAN RIGHTS: MONITORING PETITIONS AGAINST BRAZIL (2006-15)

Ianá Priscilla de Oliveira Silva

Graduada en Derecho por la UFAL, becaria PIBIC 2014-2015 en el Proyecto "Las Peticiones Individuales y el Sistema de Monitoreo de los Tratados de Derechos Humanos de Protección a la Mujer".

E-mail: priscilla.iana@hotmail.com.

Alessandra Marchioni

Doctora en Derecho, por la UFSC, profesora del Curso de Derecho de la UFAL, coordinadora y orientadora de investigación en el Centro de Estudios Internacional y Medio Ambiente - NEDIMA.

E-mail: alemarchioni@hotmail.com.

Received: 2017-07-16. Accepted:2017-12-10

Resumen:Este artículo contextualiza el desarrollo de los derechos humanos de las mujeres en la contemporaneidad, haciendo hincapié del sistema regional de protección y de la Convención Americana de Derechos Humanos/1969. En este contexto, son identificados los derechos específicos relativos a la protección de las mujeres y de los órganos de control administrativo y judicial con competencia para procesar y decidir sobre las demandas propuestas. Este estudio pretende investigar la hipótesis de que el sistema de peticiones individuales o quejas (individual complaints) propuestas junto a la Comisión Interamericana de Derechos Humanos es mecanismo de 
control y mecanismo capaz de reflejar la situación de violación de los derechos contra la mujer en el país y puede funcionar como instrumento alternativo para garantizar los derechos humanos.

Palabras clave: Derechos humanos - Mujeres - Sistema Interamericano - Convención Americana.

\begin{abstract}
This article contextualizes the development of human rights of women in contemporary society, with emphasis on regional human rights system and the American Convention on Human Rights/1969. In this context, the specific rights relating to the protection of women and the administrative and judicial bodies with powers to process and act on the demands proposals are identified. This work aims to investigate the hypothesis that the system of individual petitions or complaints (individual complaints) proposed by the Inter-American Commission on Human Rights it is control and monitoring mechanisms able to mirror the situation of rights violations against women in the country and can act as alternative instruments to guarantee human rights.
\end{abstract}

Keywords: Human rights - Women - Inter-American System - American Convention.

\title{
1.INTRODUCCIÓN
}

En las últimas cinco décadas, los derechos humanos se han convertido en un asunto de interés internacional, afirmándose como una rama del derecho dotada de su propia especificidad, incluso como problema de estudio e investigación. Sin embargo, aunque los derechos humanos hayan tenido este impresionante desarrollo a través de tratados y convenciones internacionales, siguen produciendo una eficacia limitada desde el punto de vista del cumplimiento de sus obligaciones y garantías (TRINDADE.1991).

En su proceso de "juridicización”, los Pactos Internacionales de Derechos Humanos (1969) $)^{1}$, también conocidos como International Bill

1 De hecho, la Declaración Universal de Derechos Humanos (1948), aprobados por la Asamblea General de las Naciones Unidas, desempeñó un papel clave en la definición y fijación de este elenco mínimo de derechos y libertades fundamentales garantizados.

${ }^{3}$ Hasta el primer semestre de 2012, fueron hechos 47.555 registros de atención en la Central de Atención a la Mujer. A lo largo de 2011, fueron 74.984 registros. muy por debajo de los 108.491 de 2010. El tipo de registro que aparece en mayor número es sobre la violencia física contra las mujeres que puede ir desde corporales leves, graves o muy graves, intento de asesinato y asesinato. Hubo 46.838 en 2010, 45.95363 n 2011 y 26.939 hasta julio de 2012. Casos de violencia sexual como violación, explotación sexual y acoso en el trabajo aparecen en $5^{\circ}$ lugar 
of Rights, inauguraron el sistema global de protección de los derechos civiles, políticos, sociales, económicos y culturales, simultáneamente con la creación de los sistemas de protección a nivel regional, como el interamericano (PIOVESAN, 2000).

Se ampliaría el sistema global de derechos humanos, en su conjunto, con la introducción de otros tratados multilaterales que garantizaron, en especie, la protección contra las violaciones de los derechos, como la eliminación de la discriminación contra la mujer. La Convención sobre la Eliminación de la Discriminación contra la Mujer (1979), a la cual Brasil se adhirió en 1984, no sólo dirigido a erradicar la discriminación contra la mujer y sus causas, así como para estimular estrategias de promoción de la igualdad de género.

Sin embargo, aunque ha evolucionado en relación con el escenario de protección de derechos específicos, no ha enfrentado con claridad el tema de la violencia contra la mujer, que sólo se produjo con la Convención Interamericana para Prevenir, Punir y Erradicar la Violencia contra la Mujer (1994).

En este contexto, se destaca que ninguno de ellos tiene el poder de sancionar a un Estado parte que viole la convención. De esta manera, en la que además de los mecanismos originales de monitoreo y control definidos por las convenciones internacionales, la Convención Americana sobre Derechos Humanos (1969) prevé mecanismos adicionales a los que se refieren a la presentación de informes periódicos, posibilitando las denuncias de violaciones de derechos en forma de peticiones individuales o quejas presentadas por individuos, grupos de individuos u organizaciones no gubernamentales.

De hecho, basado en los datos estadísticos del UNA-SE y de la UNFPA sobre la violencia contra las mujeres, incluyendo los índices del $\mathrm{PNAD}^{2}$ nacional, este artículo tiene como objetivo principal investigar la hipótesis de que el sistema de peticiones individuales o quejas (individual complaints), establecido en la Convención Americana y propuestas ante la Comisión Interamericana, sea mecanismo de control y monitoreo capaz de reflejar la situación de violación de los derechos contra la mujer en el país, pudiendo funcionar como instrumentos alternativos de solución y garantía de los derechos humanos.

Para ello, se presentará un panorama de las principales convenciones internacionales sobre la protección de los derechos humanos de la mujer, seguido de la descripción del sistema regional americano, desde la identificación de los derechos y las garantías protegidos hasta la previsión y monitoreo de competencias de los órganos interamericanos. Finalmente, se realizará una recolección de los informes de la Comisión Interamericana contra el Estado brasileño,

con 2.318 casos en $2010,1.298$ en 2011 y 915 este año.

2 
en materia de violación al derecho de la mujer, presentadas en el período de 2006 a 2015.

\section{PANORAMA DE LA PROTECCIÓN INTERNACIONAL DE LOS DERECHOS HUMANOS DE LA MUJER}

Al final de cinco décadas de una extraordinaria evolución, el derecho internacional de los derechos humanos se afirma como una rama autónoma del derecho siendo beneficiada con su propia especificidad. Se trata esencialmente de un derecho a la protección de los seres humanos, formado por el conjunto de normas y una serie de mecanismos de supervisión y control específicos (COMPARATO, 2003).

De este modo, a diferencia de los tratados en general, en los tratados de derechos humanos la llamada autonomía de la voluntad estatal cede espacio para el fiel cumplimiento de los objetivos y propósitos por sus valores éticos y morales, tratando de ampliar la protección de los derechos de la víctima (PIOVESAN, 2000). Así, es que los tratados internacionales en materia de derechos humanos establecen al menos dos esferas de protección distintas y complementarias a la nacional, una a nivel mundial y la otra en escala regional, respectivamente sometidos a los sistemas de las Organizaciones de las Naciones Unidas y de los Estados Americanos.

En este sentido, el criterio de selección de la norma aplicable deberá utilizar el criterio de la primacía de la norma más benéfica a las personas protegidas (TRINDADE, 1991). Aunque ambas las normativas internacionales son sistemas complementarios al nacional, es posible identificar una clara inflexión no judicial de solución de controversias en el sistema onusiano, diferente del sistema interamericano que prevé una solución predominantemente judicial. (PIOVESAN, 2000)

En 1979, impulsada por la proclamación en 1975, declarado el Año Internacional de la Mujer, y por la Conferencia Internacional de la Mujer en el mismo año, las Naciones Unidas aprobaron la Convención sobre la eliminación de todas las formas de discriminación contra la mujer. Aunque ampliamente aceptada por la comunidad internacional, en la época, más de 100 ratificaciones, ante la paradoja de ser el instrumento internacional de protección que más recibió número de reservas sustanciales ${ }^{3}$.

3 De los 100 Estados que inicialmente ratificaron el Tratado, 23 realizaron reservas, de las cuales 88 fueron sustanciales al texto. La mayoría de las reservas sobre la presentación de conflictos relativos a la interpretación del tratado a la jurisdicción de la Corte Internacional de Justicia (art. 29); otros se refieren a la adopción de acciones afirmativas sobre la eliminación de prejuicios y estereotipos (art. 5) y la eliminación de la discriminación política y vida pública (art. 7). Dichas reservas incompatibles con el objeto y propósito de la Convención contradicen 
En estos términos, se debe señalar que materia de protección de la mujer, el Estado brasileño ha incorporado a esta Convención Internacional en 1984, con reservas iniciales de algunos dispositivos ${ }^{4}$, más tarde superadas por el contenido constitucional actual. Según el art. 1 de la Convención Internacional sobre la discriminación contra la mujer: "cualquier distinción, exclusión o restricción basada en el sexo que tiene por objeto o resultado perjudicar, anular el reconocimiento, la base de la igualdad de hombres y mujeres, de los derechos humanos y de las libertades fundamentales en las esferas políticas, económicas, sociales, culturales y civiles". Cabe señalar que la Convención Internacional, no enfrenta la temática de la violencia contra la mujer de manera explícita (AMARAL, 2006).

Dado este hecho, en 1993, las Naciones Unidas adoptaron la Declaración sobre la Eliminación de la Violencia contra la Mujer, que la define como "cualquier acto de violencia de género que resulte o pueda resultar en daño físico, sexual, psicológico o sufrimiento de la mujer, incluyendo amenazas y actos, coerción o privación arbitraria de la libertad, pudiendo producirse en la esfera pública o en la esfera privada", no adoptada por Brasil.

En el contexto de las normas regionales de protección de los derechos humanos, el país se comprometió con la Convención Americana sobre Derechos Humanos/1969 o "Pacto de San José de Costa Rica", al que se unió en 1992. Esta Convención no trata específicamente sobre el derecho de la mujer, sino remite a las protecciones y garantías de las libertades individuales en general, incluyendo el derecho a la integridad personal (art. 5) y la libertad personal (art. 7).

Unos años más tarde, el país se unió en $1995^{5}$, a la Convención Interamericana para Prevenir, Punir y Erradicar la Violencia contra la Mujer/1994, también llamada "Convención Belén do Pará". La Convención Interamericana reconoce que la violencia contra la mujer constituye una violación de los derechos humanos y las libertades fundamentales de forma que limitar total o parcialmente el reconocimiento, goce y ejercicio de tales derechos y libertades, incorporando muchos conceptos de la Declaración de Viena de 1993 de las Naciones Unidas. Fue "[...] el tratado con el mayor número de ratificaciones dentro de los sistemas regionales de protección de los derechos humanos "(NEGREIROS, 2010).

Así, basado en el contenido de este derecho internacional, en materia de derechos humanos de la mujer, especialmente en materia

por lo menos la Convención de Viena sobre Derechos de los Tratados de 1969, en su art. 19.

4 El Decreto Legislativo n. 93 de 14 de noviembre de 1983 hizo reservas a los arts. $15 \S 4$ sobre la libertad en la elección de domicilio y al art. $16 \S 1$ letras $a, c, g$ y $h$., sobre la igualdad de derechos en el matrimonio y en las relaciones familiares.

5 Decreto $\mathrm{n}^{\circ} 1.973$ de 1996. 
de prevención, cohibición y punición de prácticas que causen la violencia contra la mujer, se observa la predicción de un conjunto de mecanismos de control y monitoreo de los tratados que van más allá de los tradicionales informes periódicos elaborados por los Estados partes, que son peticiones individuales o quejas (individual complaints).

En efecto, en función de resultados preliminares, las peticiones han sido herramientas de gran alcance en la denuncia de desobediencias por parte del Estado brasileño al "Pacto de San José", como queda claro en el contenido de la Recomendación 54/2001 de la Comisión Interamericana sobre el caso de Maria da Penha. Para confirmar esta hipótesis, se realizó un sondeo de las acciones perpetradas contra el Estado Brasileño en el periodo 2002-2012 y el análisis de los criterios de admisibilidad de las peticiones de los informes de la Comisión Interamericana.

\section{CONVENCIÓN AMERICANA SOBRE DERECHOS HUMANOS (PACTO DE SAN JOSÉ DE COSTA RICA) Y SUS DISPOSITIVOS DE MONITOREO Y CONTROL}

\section{La Convención Americana sobre Derechos Humanos,} negociada en San José de Costa Rica el 22/11/1969, entró en vigor internacionalmente el 18/07/1978, tras el $11^{\circ}$ (undécimo) depósito de un instrumento de ratificación o de adhesión en la Secretaría General de la Organización de los Estados Americanos, en los términos de su art. 74-2, entrando en vigor, para los demás Estados, en la fecha del depósito de su instrumento de ratificación o de adhesión. En este sentido, la Convención Americana sobre Derechos humanos cuenta con 19 signatarios $^{6}$ y 25 instrumentos de ratificación/adhesión depositados, de entre el total de 35 (treinta y cinco) países americanos ${ }^{7}$. Brasil recibió el Pacto de San José en su ordenamiento el 26.05.1992, a través

$6^{7}$ Entre los signatarios, sólo los Estados Unidos nunca depositaron instrumento de ratificación o de adhesión a la Convención. (OEA. CIDH, 2017).

$7^{8}$ Antigua y Barbuda, Bahamas, Belice, Canadá, Cuba, Guyana, San Cristóbal y Nieves, Santa Lucía, San Vicente y las Granadinas son los Estados que no han firmado o adherido al Pacto, en el caso del Estado cubano, en 2009, durante la 39a Asamblea General de OEA se ha convertido en sin efecto la Resolución que excluía a Cuba de la Organización en 1962, dando lugar a su reintegración. Antes de eso, la Comisión Interamericana de Derechos Humanos abogó por la colocación de la exclusión de ese país, efectuada por medio de la Resolución VI de la Octava Reunión de Consulta de Ministros de las Relaciones Exteriores, compuesto por sólo el Gobierno cubano y no el Estado miembro, haciendo hincapié en la diferencia entre los conceptos jurídicos del Estado y Gobierno, manteniendo el Estado cubano como miembro participante del sistema interamericano y ,por lo tanto, responsable por los compromisos asumidos con la Declaración Americana de los Derechos y Deberes del Hombre y con la Carta de la Organización de Estados Americanos. (OEA. CIDH, 2017). 
del Decreto Legislativo $\mathrm{n}^{\circ} .27$, de 26.05.1992 y Decreto $\mathrm{n}^{\circ}$. 678, de 25.09.1992.

Aparte de ratificar el Pacto, los Estados pudieron reconocer o no la competencia de la Corte Interamericana de Derechos Humanos para todos los casos relativos a la interpretación o aplicación de la Convención (art. 62 - 1) y la competencia de la Comisión Interamericana para los casos de peticiones específicas presentadas por los Estados Partes contra Estados Partes (art. 45-1). De entre los 25 países que ratificaron/se adhirieron al Pacto, tres no aceptaron la competencia de la Corte ${ }^{8}$ y quince no aceptaron la competencia de la Comisión ${ }^{9}$, en los términos anteriormente expuesto. Cabe subrayar que la competencia de la Comisión para apreciar los casos de violaciones de Estados contra sus nacionales no depende de declaración expresa, siendo inherente a la ratificación del Pacto.

La interpretación del texto de la Convención no puede implicar en supresión, limitación o exclusión del goce o ejercicio de los derechos previstos, excepto en los casos de guerra, peligro público u otra emergencia afín (art. 29), en este último caso, las garantías previstas en el Pacto pueden suspenderse por tiempo limitado, siempre $\mathrm{y}$ cuando no pongan fin a la discriminación y no alcancen los derechos determinados en los artículos 3 (personalidad jurídica), 4 (vida), 5 (integridad personal), 6 (prohibición de esclavitud y servidumbre), 9 (legalidad y retroactividad), 12 (libertad de conciencia y de religión), 17 (protección de la familia), 18 (derecho al nombre), 19 (derechos del niño), 20 (nacionalidad) y 23 (derechos políticos) o su protección de garantías esenciales, en virtud del art. 27.

Además, el texto de la Convención trata de la posibilidad de realización de reservas ${ }^{10}(\operatorname{art} .75)$, sobre la posibilidad de proposiciones de enmiendas al texto, con sumisión de propuestas por los Estados partes, Comisión o Corte a la Asamblea General (art. 76) o protocolos facultativos, con propuesta por los Estados partes o por la Comisión ${ }^{11}$

8 Dominica, Grenada y Jamaica. El Perú reconoció la competencia de la Corte en 1981, este reconocimiento fue retirado en 1999 y volvió a reconocer el 29.01.2001, con vigencia ininterrumpida a partir del depósito de su instrumento de ratificación el 21.01.1981. (OEA. CIDH, 2017).

9 Barbados, Bolivia, Brasil, Dominica, El Salvador, Grenada, Guatemala, Haití, Honduras, México, Panamá, Paraguay, República Dominicana, Suriname y Trinidad y Tobago. (OEA. CIDH, 2017).

10 De los 25 países que se unieron a la Convención, sólo Bolivia, Colombia, Costa Rica, Ecuador, El Salvador, Grenada, Guatemala, Haití, Honduras, Jamaica, Nicaragua, Panamá, Paraguay, Surinam no hicieron ninguna reserva o declaración interpretativa. La Declaración tuvo lugar solo Brasil: "El gobierno de Brasil considera que los artículos 43 y 48, d, no incluyen el derecho automático de visitas e investigaciones in loco de la Comisión Interamericana de Derechos Humanos, que dependerán de la ausencia expresa del estado". (OEA. CIDH, 2017).

11 La Convención tiene solamente un protocolo facultativo, el protocolo adicional a la 
(art. 77), para incluir otros derechos y libertades, y sobre la denuncia a la Convención que puede ocurrir tras cinco años de su entrada en vigor (art. 78-1 y 78-2) ${ }^{12}$.

La Convención Americana trae en su seno el compromiso hecho entre los Estados partes para respetar los derechos y libertades reconocidos en ella y garantizar su pleno y libre ejercicio a toda persona, sin discriminación alguna, por motivos de raza, color, sexo, idioma, religión, opiniones políticas o cualquier otra índole, origen nacional o social, posición económica, nacimiento o cualquier otra condición social.

En total, el Pacto de San José de Costa Rica lista 23 (veintitrés) derechos y garantías, distribuidos en 02 (dos) capítulos (II. De los Derechos Civiles y Políticos y III. De los Derechos Económicos, Sociales y Culturales $)^{13}$ : Derecho al Reconocimiento de la Personalidad Jurídica (art. 3), Derecho a la Vida (art. 4) ${ }^{14}$, Derecho a la Integridad Personal (art. 5) $)^{15}$, Prohibición de la Esclavitud y Servidumbre (art. 6), Derecho a la Libertad Personal (art. 7), Garantías Judiciales (art. 8) ${ }^{16}$, Principio de Legalidad y de la Retroactividad (art. 9), Derecho a la Indemnización (art. 10) $)^{17}$, Protección del Honor y de la Dignidad (art. 11), Libertad de

Convención Americana sobre Derechos Humanos en materia de Derechos Económicos, Sociales y Culturales - Protocolo de San Salvador (firmado el 17.11.1988), con dieciséis y quince firmas y quince ratificaciones/Adhesiones. Chile, Haití, Nicaragua, República Dominicana y Venezuela lo firmaron, pero no lo ratificaron, mientras que Brasil, Colombia, Honduras y Suriname no lo firmaron, pero sí lo ratificaron a posteriori. (OEA. CIDH, 2017).

12 En esos términos, Trinidad y Tobago denunció la Convención el 26.05.1998, con vigencia a partir de 26.05.1999. (OEA. CIDH, 2017).

13 Además, el Convenio establece, en su capítulo V, art. 32, los Deberes de las Personas, en el marco de la correlación entre Derechos y Obligaciones, que son: "1. Toda persona tiene deberes para con la familia, la comunidad y la humanidad; 2. Los Derechos de cada persona están limitados por los derechos de los demás, por la seguridad de todos y por las justas demandas del bien común, en una sociedad democrática “. (OEA. CIDH, 2017).

14 Barbados, Guatemala, Trinidad y Tobago formularon reserva a este artigo este artículo, teniendo en cuenta que sus ordenamientos jurídicos internos preveían la posibilidad de la pena de muerte, siendo posteriormente retirada la reserva sólo por Guatemala. México hizo una declaración interpretativa en el sentido de que no entiende que no existe obligación de adoptar o mantener en vigor legislación que proteja la vida desde la concepción, puesto que el asunto sería de dominio exclusivo de los Estados. (OEA. CIDH, 2017).

15 Dominica hizo una declaración interpretativa al artículo interpretativo, de modo que no se interprete como prohibición a castigos corporales, ya que el país tiene una Ley de Castigo Corporal y la ley de Castigo de Menores Delincuentes. (OEA. CIDH, 2017).

16 Dominica y Barbados hicieron recientemente reserva al derecho irrenunciable a la asistencia de defensor proporcionado por el Estado, en casos donde el acusado no se defienda solo o nombre defensor en el plazo legal. (OEA. CIDH, 2017).

17 La Argentina ha presentado una declaración interpretativa de ese artículo para que el error judicial que implique la obligación de indemnizar sea establecido por un tribunal nacional. (OEA. CIDH, 2017). 
Conciencia y de Religión (art. 12), Libertad de Pensamiento y Expresión (art. 13), Derecho de Rectificación o Respuesta (art. 14), Derecho de Asamblea (art. 15), Libertad de Asociación (art. 16), Protección de la Familia (art. 17), Derecho a un Nombre (art. 18), Derechos del Niño (art. 19), Derecho a la Nacionalidad (art. 20), Derecho a la Propiedad Privada (artículo 21) ${ }^{18}$, Derecho de Circulación y de Residencia (art. 22), Derechos Políticos (art. 23) ${ }^{19}$, Igualdad Ante la Ley (art. 24), Protección Judicial (artículo 25) y Desarrollo Progresivo (art. 26).

Sobre el control externo ejercido por la comunidad internacional cuando un Estado se enlaza a una Convención y asume los deberes y obligaciones derivados, Piovesan hace los siguientes apuntes:

Al acoger el aparato internacional de protección, así como obligaciones internacionales que se derive de él, el Estado pasa a aceptar el monitoreo internacional, con respecto a la forma por el cual los derechos fundamentales son respetados en su territorio. El estado pasa, así, a permitir el control $y$ seguimiento de la comunidad internacional, cuando, en casos de violación de derechos fundamentales, la respuesta de las instituciones nacionales se muestra insuficiente y falla, o, a veces inexistente. Se enfatiza, sin embargo, que la acción internacional es siempre una acción suplementaria, constituyendo una garantía adicional de protección de los derechos humanos (PIOVESAN, 2003, p. 61).

En este sentido, al comprometerse con la Convención, el Estado tiene el deber de someterse a los mecanismos de control establecidos por ella.

Para el cumplimiento de tales derechos, el acto crea dos

18 Aunque reconoce el Derecho a la propiedad privada y a la indemnización justa en caso de expropiación por razones de utilidad pública o interés social, el Chile, se reserva el derecho de que la Comisión y la Corte, al abordar la cuestión, no pueden comentar sobre las razones de utilidad pública o interés social que hayan sido utilizadas por el Estado como fundamento para privar a la persona de su propiedad. La Argentina hizo reserva indicando que no serán sometidas a revisión cuestiones relativas a la política económica del gobierno, las causas de utilidad pública e interés social, o lo que se entienda por una indemnización justa. (OEA. CIDH, 2017).

19 El Uruguay formuló reservas en relación con este artículo, puesto que la Constitución prevé la posibilidad de suspender la ciudadanía de las personas condenadas a pena de prisión. El México también formuló reserva al artículo, considerando que su Carta Magna dispone que los ministros de los cultos no tendrán derecho a voto, activo o pasivo, ni el derecho de asociación con fines políticos. (OEA. CIDH, 2017). 
mecanismos de control: peticiones e informes. Las peticiones son instrumentos de control que contienen denuncias o quejas de violación de la Convención por un Estado parte, se presentarán a la Comisión o a la Corte y puede presentarse en dos formas que se difieren sólo por sujetos que pueden interponerlas junto a la Comisión. Las peticiones generales (art. 44) son las que pueden ser presentadas por cualquier persona o grupo de personas o entidad no gubernamental legalmente reconocida. Por otra parte, las Peticiones Específicas son las que contienen comunicaciones hechas por un Estado parte con la alegación de violación de los derechos reconocidos en la Convención por otro Estado parte (art. 45), se considera sólo cuando ambos Estados reconocen la competencia de la Comisión para recibir este tipo de comunicación.

Los informes se presentan en diferentes momentos de la Convención: a) como función de la Comisión Interamericana de Derechos Humanos, que deberá presentar un informe anual a la Asamblea General de la Organización de Estados Americanos (art. 41, g); b) como obligación de los Estados Partes, que deberán presentar a la Comisión una copia de los mismos que deberán ser enviados a las Comisiones Ejecutivas del Consejo Interamericano Económico y Social y del Consejo Interamericano para la Educación, Ciencia y Cultura (art. 42); y c) como parecer final de la Comisión, en los casos que alcance o no una solución a las peticiones o comunicaciones a ella presentadas (arts. 48, 49, 50 y 51).

Además de estos mecanismos de control, el Pacto dispone para la competencia de dos órganos encargados de conocer las cuestiones relacionadas con la Convención, siendo uno de control administrativo (Comisión Interamericana de Derechos Humanos) y uno de control jurisdiccional (Corte Interamericana de Derechos Humanos).

La Comisión es tratada en 18 artículos en el texto de la Convención, los cuales disponen sobre su Organización (arts. 34 a 40), Funciones (arts. 41 a 43), Competencia (arts. 44 a 47) y Procedimientos en la Comisión (arts. 48 a 51).

La Comisión estará compuesta de siete miembros elegidos por la Asamblea General de la lista de candidatos propuestos por los gobiernos de los Estados miembros y no puede estar compuesta de más de un nacional del mismo Estado, con mandatos de cuatro años, con posibilidad de reelección. La Comisión representará todos los miembros de la OEA y contará con estatuto y reglamento propios.

Su función principal es promover la observancia y defensa de los derechos humanos y, por eso, sus responsabilidades son: estimular la conciencia de los derechos humanos en los pueblos de América, formular recomendaciones a los gobiernos de los Estados miembros en materia de derechos humanos, preparar estudios o informes que considere convenientes para el desempeño de sus funciones, solicitar 
información a los Estados miembros en materia de derechos humanos, cumplir con las consultas y prestar asesoramiento sobre los derechos humanos a los Estados que lo soliciten, actuar con respecto a las peticiones y otras comunicaciones de su competencia, presente informe anual a la Asamblea General de la OEA.

Posee Jurisdicción para examinar las peticiones generales presentadas por personas, grupos de personas o entidades no gubernamentales contra los Estados partes y, reconocida la competencia por los Estados miembros, también para apreciar peticiones específicas de Estado parte contra Estado parte.

El procedimiento ante la Comisión será mejor analizado cuando sean presentados los resultados del análisis de peticiones impetradas como mecanismo de control previsto en la Convención.

La Corte Interamericana de Derechos Humanos aparece en 18 (dieciocho) artículos, de modo que el texto del Pacto dispone sobre su organización (arts. 52 a 60), Competencias y Funciones (arts. 61 a 65) y como es el procedimiento ante la Corte (arts. 66 a 69).

La Corte estará compuesta de siete jueces, nacionales de los Estados miembros y no puede haber dos jueces de la misma nacionalidad, que son elegidos por seis años, con posibilidad de reelección. El quorum para las deliberaciones en la Corte es de cinco jueces y la Comisión comparecerá a todos los casos ante la Corte. La Corte elaborará su propio estatuto, que será sometido a la aprobación de la Asamblea General y contará con su propio regimiento.

$\mathrm{Su}$ función principal es conocer los casos relativos a la interpretación y aplicación de las disposiciones de la Convención.

Solamente los Estados partes y la Comisión pueden someter casos a la decisión de la Corte, y para eso es necesario que haya sido agotado el procedimiento de análisis ante la Comisión. La Corte funcionará sólo en casos donde los Estados partes hayan reconocido su competencia, sea incondicionalmente o bajo condición de reciprocidad.

Sus decisiones implican determinar que sea asegurado al perjudicado el disfrute del derecho o libertad violados, que sean reparadas las consecuencias de la medida o situación de la violación y/o el pago de indemnización, pudiendo tomar decisiones de carácter permanente y, algunos casos de ex5trema gravedad y urgencia y cuando sea necesario para evitar daños irreparables, pueden adoptar medidas provisionales que se aplican.

Además, la Corte podrá ser consultada por los Estados miembros de la interpretación de la Convención y podrá emitir pareceres sobre la compatibilidad de leyes internas con el texto del Pacto y, aún, con la Carta de la OEA, a solicitud de un Estado miembro.

La sentencia de la Corte deberá basarse y tendrá carácter definitivo e indiscutible y puede haber solicitud de interpretación, en un 
plazo de 90 días, sobre el sentido o alcance de la sentencia. Los Estados partes en la Convención, que acepten la jurisdicción de la Corte, se comprometen a cumplir con sus decisiones, en los casos en que sean partes.

\section{EL SISTEMA DE MONITOREO DE LA CONVENCIÓN AMERICANA SOBRE DERECHOS HUMANOS/1969 Y LAS PETICIONES INDIVIDUALES EN MATERIA DE DERECHOS HUMANOS DE LA MUJER - ANÁLISIS DE LOS INFORMES (2006-2015)}

Para el análisis del sistema de monitoreo de la Convención Americana sobre Derechos Humanos fueron recolectados y seleccionados datos extraídos de informes anuales de la Comisión Interamericana sobre Derechos Humanos en su página oficial ${ }^{20}$, según la clasificación proporcionada por la Comisión, los informes se clasifican en: a) informes presentados a la Asamblea General de la OEA (art. 41, g del Pacto), b) informes de solución amistosa de la demanda (art. 49) c) informes en que no se ha llegado a una solución amistosa de la demanda (art. 50), d) informes de archivos (arte. 48.1. b) y e) informes de admisibilidad de peticiones presentadas a la Comisión (arts. 46, 47 y 48). ${ }^{21}$

Además de presentar la clasificación mencionada, los informes dispuestos por la Comisión permiten el acceso a toda la información publicada de casos contra los Estados partes presentados a la competencia de la Comisión, con fundamento en cualquiera de las Convenciones a las que sea órgano de control.

De ese modo, fue posible seleccionar sólo peticiones individuales o quejas contra el estado brasileño, por motivos de violaciones de los derechos reconocidos en el Pacto de San José, entre los años de 2006 a 2015, en relación con las peticiones en que las mujeres aparecen en condición de peticionarias o víctimas, con el fin de verificar si el Sistema Regional de Protección de los Derechos Humanos funciona como un mecanismo para la protección más rápida y eficaz que el sistema de protección nacional.

20 OEA. CIDH. Publicaciones. Informes anuales. Disponible en: < http://cidh.oas.org/ Publicacoes.htm $>$.

Acceso el: 20 ene. 2017.

21 La Comisión no publica informes intermediarios sobre el progreso de las demandas desde su protocolización hasta la publicación de los informes mencionados, o hace imposible realizar un análisis detallado de los elementos relativos a plazos y duración de los procedimientos dentro de la Comisión. 
TABLA 1 - Panorama General de las peticiones contra Brasil (2006-2015)

\begin{tabular}{|c|c|c|c|c|c|c|c|c|c|c|}
\hline SITUACIÓN & ఫ్సి & ક્సิ & క్సి & હે & 을 & בี & ฮี้ & 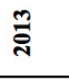 & تृ & 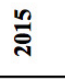 \\
\hline Peticiones recibidas & 1325 & 1456 & 1323 & 1431 & 1598 & 1658 & 1936 & 2061 & 1758 & 2164 \\
\hline $\begin{array}{l}\text { Peticiones pendientes } \\
\text { de análisis inicial }\end{array}$ & - & - & - & - & - & 6134 & 7208 & 8548 & 9039 & 9673 \\
\hline $\begin{array}{c}\text { Peticiones con la } \\
\text { decisión de no iniciar } \\
\text { el trámite }\end{array}$ & 562 & 880 & 880 & 1395 & 712 & 789 & 674 & 613 & 1039 & 876 \\
\hline $\begin{array}{c}\text { Peticiones con la } \\
\text { decisión de iniciar el } \\
\text { trámite }\end{array}$ & 147 & 118 & 118 & 120 & 276 & 262 & 137 & 123 & 284 & 208 \\
\hline $\begin{array}{l}\text { Total de decisiones } \\
\text { sobre apertura }\end{array}$ & 709 & 998 & 998 & 1515 & 988 & 1051 & 811 & 736 & 1323 & 1084 \\
\hline $\begin{array}{c}\text { Informes de } \\
\text { Inadmisibilidad }\end{array}$ & 14 & 14 & 10 & 15 & 10 & 11 & 17 & 9 & 4 & 2 \\
\hline $\begin{array}{l}\text { Informes de } \\
\text { Admisibilidad }\end{array}$ & 56 & 51 & 49 & 62 & 73 & 66 & 42 & 44 & 47 & 42 \\
\hline $\begin{array}{l}\text { Peticiones sobre } \\
\text { Admisibilidad }\end{array}$ & - & - & - & - & - & - & - & - & 1379 & 1392 \\
\hline Casos de Mérito & - & - & - & - & - & - & - & - & 576 & 511 \\
\hline $\begin{array}{c}\text { Informes de Mérito } \\
\text { Publicados }\end{array}$ & 8 & 4 & 7 & 13 & 4 & 5 & 1 & 3 & 3 & 5 \\
\hline $\begin{array}{c}\text { Informes de Solución } \\
\text { Amistosa }\end{array}$ & 10 & 5 & 4 & 4 & 11 & 8 & 8 & 6 & 6 & 5 \\
\hline $\begin{array}{c}\text { Peticiones y casos en } \\
\text { trámite }\end{array}$ & 1237 & 1251 & 1376 & 1450 & 1584 & 1645 & 1704 & 1753 & 1955 & 1903 \\
\hline Decisiones de Archivo & 27 & 10 & 0 & 20 & 55 & 54 & 42 & 38 & 29 & 107 \\
\hline $\begin{array}{c}\text { Casos enviados a la } \\
\text { Corte IDH }\end{array}$ & 14 & 14 & 9 & 11 & 16 & 23 & 12 & 11 & 19 & 14 \\
\hline $\begin{array}{c}\text { Solicitudes de } \\
\text { Medidas Cautelares }\end{array}$ & - & - & 301 & - & 375 & 422 & 448 & 400 & 504 & 674 \\
\hline $\begin{array}{c}\text { Medidas Cautelares } \\
\text { Otorgadas }\end{array}$ & 37 & 40 & 28 & 34 & 68 & 57 & 35 & 26 & 33 & 45 \\
\hline
\end{tabular}

Fuente: Elaborada por las autoras, basado en datos estadísticos facilitados por la Comisión IDH en: http://www.oas.org/es/cidh/multimedia/estadisticas/estadisticas.html >.

En este sentido, de las informaciones contenidas en la tabla 1, es posible extraer que hay un gran déficit de publicaciones de la Comisión IDH. Véase, por ejemplo, que en el año 2006 fueron 147 (ciento cuarenta y siete) decisiones favorables a las peticiones para el inicio del proceso, mientras que sólo 56 (cincuenta y seis) informes de admisibilidad. Del mismo modo, hubo 562 (quinientas sesenta y dos) decisiones de inadmisibilidad, con la publicación de solamente 14 (catorce) informes de inadmisibilidad. Incluso más evidente es la diferencia entre el total de casos de mérito para el período analizado (1087) y las publicaciones de informes de análisis de mérito (53).

Todavía con respecto a la tabla 1 , en el período 2006-2015, solamente en relación a Brasil, fueron recibidas por la Comisión IDH, el total de 16.710 (dieciséis mil setecientos diez peticiones), con 1.379 y 1.392 en proceso de admisibilidad en los años de 2014 y 2015 , respectivamente. El indicador "Total de decisiones sobre apertura" (Tabla 1, línea 6), presenta el número total de peticiones que han sido analizadas por la Secretaría de Comisión IDH, así, restando este valor 
del número de peticiones recibidas, hay un vacío de 6.491 (seis mil cuatrocientos noventa y una) peticiones que no han pasado todavía por la etapa inicial de análisis de la Comisión.

Los números dejan claro, en primer lugar, que la búsqueda de la protección internacional de los derechos humanos en la Comisión no es baja, por el contrario, más de 1.200 (mil doscientas) peticiones al año, sin embargo, la respuesta que ha sido dada por la Comisión no ha atendido satisfactoriamente a las demandas presentadas.

Aunque la propia Comisión, en la tabla 1, hace referencia a 532 (quinientos treinta y dos) informes de admisibilidad, 106 (ciento seis) de inadmisibilidad, 53 (cincuenta y tres) informes de mérito y 382 (trescientos ochenta y dos) decisiones de archivo, en los informes anuales publicados se identificaron, en total solamente 99 (noventa y nueve), informes sobre las peticiones presentadas contra Brasil (tabla 2 abajo), siendo 54 (cincuenta y cuatro) de admisibilidad, 11 (once) de inadmisibilidad, 01 (una) de solución amistosa, 05 (cinco) de análisis de mérito y 28 (veintiocho) de archivo. Esto significa que aproximadamente el 91\% (noventa y un por ciento) de los informes no han sido publicados, o 974 (novecientos setenta y cuatro) informes no han sido localizados en las publicaciones oficiales de la Comisión y, una vez más, sólo con relación a Brasil.

\begin{tabular}{|c|c|c|c|c|c|c|}
\hline \multirow[b]{2}{*}{ AÑ̃O } & \multicolumn{6}{|c|}{ SITUACIÓN } \\
\hline & ADMISIÓN & INADMISIÓN & $\begin{array}{l}\text { SOLUCIÓN } \\
\text { AMISTOSA }\end{array}$ & MÉRITO & ARCHIVO & $\begin{array}{l}\text { TOTAL } \\
\text { POR AÑo }\end{array}$ \\
\hline 2006 & 06 & 00 & 01 & 01 & 00 & 08 \\
\hline 2007 & 07 & 01 & 00 & 00 & 00 & 08 \\
\hline 2008 & 06 & 00 & 00 & 01 & 00 & 07 \\
\hline 2009 & 07 & 06 & 00 & 02 & 00 & 15 \\
\hline 2010 & 10 & 00 & 00 & 01 & 06 & 17 \\
\hline 2011 & 06 & 00 & 00 & 00 & 03 & 09 \\
\hline 2012 & 08 & 03 & 00 & 00 & 06 & 17 \\
\hline 2013 & 01 & 01 & 00 & 00 & 02 & 04 \\
\hline 2014 & 02 & 00 & 00 & 00 & 00 & 02 \\
\hline 2015 & 01 & 00 & 00 & 00 & 11 & 12 \\
\hline TOTAL POI & & & & & & \\
\hline SITUACIÓN & 54 & 11 & 01 & 05 & 28 & 99 \\
\hline
\end{tabular}

Es importante aclarar que, no necesariamente cada informe se refiere a un caso diferente, porque los casos de solución amistosa, de mérito y de archivo pueden referirse a casos ingresados en el mismo período, lo que daría lugar a dos informes distintos para el mismo caso. Dicho esto, si consideramos que, hipotéticamente, los informes de solución amistosa y de mérito publicados se refieren a admitidas en el mismo período, se llega a la conclusión que aproximadamente el $11 \%$ (once por ciento) de los casos admitidos por la Comisión alcanzaron 
una respuesta definitiva.

De esos 99 (noventa y nueve) informes, los que versaron sobre la violación de los derechos humanos, teniendo a mujeres como peticionarias o víctimas, fueron 18 (dieciocho), es decir, un $18 \%$ (dieciocho por ciento) del total, con fundamento en el Pacto de San José, como se detalla a continuación:

\begin{tabular}{|c|c|c|c|c|c|c|}
\hline \multirow[b]{2}{*}{ AÑO } & \multicolumn{6}{|c|}{ SITUACIÓN } \\
\hline & ADMISIÓN & INADMISIÓN & $\begin{array}{l}\text { SOLUCIÓN } \\
\text { AMISTOSA }\end{array}$ & MÉRITO & ARCHIVO & $\begin{array}{l}\text { TOTAL } \\
\text { POR AÑO }\end{array}$ \\
\hline 2006 & 01 & 00 & 00 & 01 & 00 & 02 \\
\hline 2007 & 01 & 00 & 00 & 00 & 00 & 01 \\
\hline 2008 & 01 & 00 & 00 & 00 & 00 & 01 \\
\hline 2009 & 01 & 00 & 00 & 00 & 00 & 01 \\
\hline 2010 & 03 & 00 & 00 & 00 & 00 & 03 \\
\hline 2011 & 01 & 00 & 00 & 00 & 00 & 01 \\
\hline 2012 & 02 & 02 & 00 & 00 & 01 & 05 \\
\hline 2013 & 01 & 00 & 00 & 00 & 01 & 02 \\
\hline 2014 & 00 & 00 & 00 & 00 & 00 & 00 \\
\hline 2015 & 00 & 00 & 00 & 00 & 02 & 02 \\
\hline $\begin{array}{l}\text { TOTAL } \\
\text { POR } \\
\text { SITUACIÓN }\end{array}$ & 11 & 02 & 00 & 01 & 04 & 18 \\
\hline
\end{tabular}

La Tabla 3, en ese caso, se muestra aún más preocupante que la anterior, lo que representa aproximadamente un $0.10 \%$ (un centésimo) del número total de solicitudes sometidas a la apreciación de la Comisión en el período (véase tabla 1). Además, que, entre los 18 (dieciocho) informes, apenas 01 (uno) presenta respuesta definitiva a la demanda, que representa algo más del $8 \%$ (ocho por ciento) del número total de peticiones admitidas en las condiciones descritas en este período, de no haber logrado éxito, hasta ahora, en la resolución de los casos mediante el procedimiento de solución amistosa.

Con respecto a los informes de admisibilidad publicados por la Comisión es importante tener en cuenta que su fundamento se encuentra en los arts. 46.1 del Pacto de San José de 31 a 34 del reglamento interno de la Comisión, que cuentan con cuatro requisitos para que una petición sea considerada admisible:

a) agotamiento de recursos internos - toma en consideración si fueron interpuestos y agotados los recursos de jurisdicción interna en el Estado parte, basado en la idea de que tal requisito actúa como una garantía para que el Estado parte tenga la oportunidad de resolver los casos internamente y evitar la interferencia arbitraria de la competencia internacional al no 
ordenamiento patrio. Este requisito prevé algunas excepciones que se tratarán a continuación;

b) fecha límite de presentación de la petición - generalmente el período es de seis meses después de la notificación de la decisión definitiva de la jurisdicción interna, sin embargo, si se aplica cualquiera de las excepciones previstas, la petición debe presentarse en un plazo razonable, a criterio de la Comisión;

c) ausencia de duplicidad del procedimiento y cosa juzgada - en la jurisdicción internacional;

d) caracterización de posible violación de las disposiciones de la Convención - en este primer momento (informe de admisibilidad), la Comisión no analiza el mérito del caso, decidiendo si en realidad configura la efectiva violación de los derechos protegidos por la Convención, pero sólo compara los hechos descritos por las partes a las disposiciones del Pacto para verificar aquellos hechos, si se confirman, podrían conducir a una posible violación de tales dispositivos y por lo tanto, la petición es admitida en este punto;

Los requisitos a y b contienen algunas excepciones: a) ausencia, en la legislación interna del Estado parte, del debido proceso legal para la protección del derecho que se alegue que haya sido violado; b) imposibilidad de acceso o agotamiento, por el perjudicado, a los recursos de jurisdicción interna; y c) demora en la decisión sobre los mencionados recursos. Cabe destacar todavía que en los casos donde el peticionario no cumple con el requisito de agotamiento de recursos internos, el plazo de presentación de la petición se considerará "razonable", a través de análisis discrecional de la Comisión que tendrá en cuenta la fecha de violación de los derechos y las circunstancias específicas del caso en concreto.

Encuanto a los casos con publicación del informe deadmisibilidad, estos se examinarán en detalle, ya que ofrece informaciones detalladas sobre la atención a los requisitos de admisibilidad establecidos en la Convención y en el Reglamento Interno de la Comisión IDH, los derechos reconocidamente violados y el lapso temporal transcurrido entre los hechos apuntados y la publicación de los informes por la Comisión, resumidos en tabla 4. 
TABLA 4 - Peticiones admitidas en la Comisión IDH contra Brasil inherentes a violaciones de derechos humanos de las mujeres - los requisitos de admisibilidad (2006-2015)

\begin{tabular}{|c|c|c|c|c|c|}
\hline \multirow[b]{2}{*}{ Caso } & \multicolumn{4}{|c|}{ Requisitos de Admisibilidad } & \multirow[b]{2}{*}{ Observaciones } \\
\hline & $\begin{array}{l}\text { Agotamiento } \\
\text { de los Recursos } \\
\text { Internos }\end{array}$ & $\begin{array}{c}\text { Plazo para } \\
\text { Presentación } \\
\text { de la Petición }\end{array}$ & $\begin{array}{c}\text { Inexistencia de } \\
\text { Duplicación de } \\
\text { Procedimientos y } \\
\text { Cosa Juzgada }\end{array}$ & $\begin{array}{l}\text { Caracterización } \\
\text { de Posible } \\
\text { Violación de } \\
\text { Dispositivos de la } \\
\text { Convención }\end{array}$ & \\
\hline Neuza y Gisele ${ }^{22}$ & No & Razonable & Sí & Sí & Excepción del art. 46.2.c \\
\hline Marcia Souza $^{23}$ & No & Razonable & Sí & Sí & Excepción del art. 46.2.c \\
\hline Margarida Alves ${ }^{24}$ & Sí & Sí & Sí & Sí & - \\
\hline Samantha Nunes ${ }^{25}$ & Sí & Sí & Sí & Sí & - \\
\hline Fátima y Maura ${ }^{26}$ & Sí & Sí & Sí & Sí & - \\
\hline $\begin{array}{l}\text { Thalita, Ana y } \\
\text { otros }\end{array}$ & No & Razonable & Sí & Sí & Excepción del art. 46.2.a \\
\hline Rosa y José Luiziz & Sí & Sí & Sí & Sí & - \\
\hline Clelia y Rita $^{29}$ & No & Razonable & Sí & Sí & Excepción del art. 46.2.a \\
\hline Nancy y Marcio ${ }^{30}$ & No & Razonable & Sí & Sí & Excepción del art. 46.2.a \\
\hline Ivete y otros ${ }^{31}$ & No & Razonable & Sí & Sí & Excepción del art. 46.2.c \\
\hline M.V.M. y P.S.R. ${ }^{32}$ & Sí & Sí & Sí & Sí & - \\
\hline
\end{tabular}

De la lectura de los datos disponibles en la tabla anterior, es posible extraer que, más de la mitad de las peticiones aceptadas por la Comisión lo fueron en razón de la aplicación de de algunas de las excepciones previstas en el art. 46.2 de la Convención Americana. Garantizando la admisibilidad de las demandas cuando no se compruebe, en la jurisdicción interna, el ejercicio del debido proceso legal para proteger el derecho violado (a), o en casos donde el perjudicado no puede acceder o agotar los recursos de jurisdicción interna (b), o cuando haya demora sin fundamento en la decisión sobre los mencionados recursos (c). En los casos mencionados arriba, la aplicaron las excepciones previstas en las letras "a" y "c" en igual proporción (50\%).

El reconocimiento de la aplicación de una de las mencionadas excepciones a subsanar la falta del requisito de agotamiento de los recursos internos atrae, como se explica en la exposición sobre el procedimiento en la Comisión, una mensuración en cuanto a la razonabilidad del plazo para la presentación de la petición a la Comisión, caso en el que considerará la fecha del hecho y circunstancias del caso en concreto.

En todos los casos analizados en la tabla 4, la Comisión reconoció la razonabilidad para los propósitos de la admisión de la petición.

Para esos casos en que han sido reconocidas algunas de las excepciones mencionadas, teniendo en cuenta las fechas de los hechos, la fecha de las últimas acciones en las jurisdicciones y las fechas de recepción de la petición por la Comisión, el tiempo promedio que se considera razonable es de 05 (cinco) años y 06 (seis) meses (de la fecha del hecho a la fecha de la última acción practicada en la jurisdicción interna). Cabe señalar que fue de 05 (cinco) años la media de tiempo transcurrido entre las fechas de los eventos y la recepción de las peticiones por la Comisión.

Interesante observar que, para las peticiones admitidas por la 
Comisión, el tiempo promedio transcurrido entre la fecha de recepción de la petición y la publicación del informe de admisibilidad fue de 06 (seis) años y 06 (seis) meses, con menor tiempo observado en el caso de Neusa y Gisele, en que transcurrieron 02 (dos) años y 10 (diez) meses.

Dicha información puede ser comparada con el tiempo previsto por la Convención Americana y por el Reglamento de la Comisión, cuyo plazo máximo previsto para la duración del procedimiento de apreciación inicial y publicación del informe de admisibilidad es 10 (diez) meses, ya considerados los plazos máximos previstos para la prorrogación. Es decir, la media real de la Comisión es aproximadamente $8 \mathrm{x}$ (ocho veces) más alto que la prevista en el el texto de la Convención y en el Reglamento de la Comisión.

Otro punto a destacar en relación con el incumplimiento de los plazos establecidos para las decisiones de la Comisión es el análisis del decurso temporal en el caso de Simone Andre Diniz (único con informe de mérito), cuyos hechos ocurrieron el 02.03.1997, con petición recibida el 10.10.1997, informe de admisibilidad publicado el 09.10.2002 e informe de mérito el 21.10.2006.

Es importante recordar que los plazos establecidos por el Pacto de San José y por el Reglamento Interno de la Comisión, para finalizar el procedimiento de análisis de mérito, con la publicación del informe correspondiente es de 3 (tres) años y 5 (cinco) meses entre la publicación del informe de admisibilidad y el informe de mérito. Sin embargo, en este caso transcurrieron 04 (cuatro) años, aparte de la predicción normativa, que se hace más grave cuando observado que, en este caso, no fueron realizados procedimientos facultativos (audiencia, investigación in loco o colecta de prueba testimonial), que reduce el tiempo máximo previsto de 2 (dos años) y 5 (cinco) meses.

Para el mismo caso de la recepción de la petición hasta la publicación del informe de mérito, 09 (nueve) años transcurridos, cuando lo ideal es 04 (años) y 03 (tres) meses.

Para el mismo caso, de la recepción de la solicitud hasta la publicación del informe de mérito, transcurrieron 09 (nueve) años, cuando lo ideal es 04 (años) y 03 (tres) meses.

Finalmente, en relación con los derechos presuntamente violados, tanto los mencionados por los peticionarios como los reconocidos por la Comisión cuando publicados los informes de admisibilidad, es buena idea señalar que pueden ocurrir tres situaciones: a) la Comisión reconoce la posible violación de todos los dispositivos alegados; b) la Comisión reconoce la posible infracción de los dispositivos alegados; y c) la Comisión agrega dispositivos no alegados por el peticionario.

La tabla a continuación presenta, en forma simplificada, comparación entre los dispositivos alegados por los peticionarios y los efectivamente reconocidos por la Comisión. 
TABLA 5 - Peticiones admitidas en la Comisión IDH contra Brasil - comparación entre los dispositivos mencionados por el peticionario y reconocidos por la Comisión (2006-2015)

\begin{tabular}{|c|c|c|}
\hline Caso & $\begin{array}{c}\text { Dispositivos Alegados por el } \\
\text { Peticionario }\end{array}$ & Dispositivos Añadidos por la Comisión \\
\hline Neuza y Gisele & Arts. 1 y 24 & Arts. 8 y 25 \\
\hline Marcia Souza & Arts. $1.1,2,4,24$ y 25 & Arts. 8.1 \\
\hline Margarida Alves & Arts. $1.1,8$ y 25 & - \\
\hline Samantha Nunes & Arts. 1.1, 5.1, 7, 11.1, 19, 24 у 25 & Arts. 8.1 \\
\hline Fatima e Maura & Arts. $1.1,8,17,19$ y 24 & Arts. 8.1 y 25 \\
\hline Thalita, Ana e outros & Arts. $4,5,11$ y 25 & Arts. $1,5.1$ y 8 \\
\hline Rosa e José Luiz & Arts. $1.1,4$ y 25 & Arts. 8 y 16 \\
\hline Clelia e Rita & Arts. $1.1,2,8,25$ y 28 & Arts. 21 \\
\hline Nancy e Marcio & $\begin{array}{c}\text { No hizo referencia a dispositivos } \\
\text { específicos }\end{array}$ & Arts. $1.1,2,8,21$ y 25 \\
\hline Ivete e outros & Arts. $4,5,11$ y $8.1,25.1$ & Arts. 1 y 5.1 \\
\hline M.V.M. e P.S.R & Arts. $1.1, \mathbf{5}, 7, \mathbf{1 1}, \mathbf{2 4}$ y 25 & Arts. 8.1 y 19 \\
\hline
\end{tabular}

Fuente: Elaborada por las autoras.

En relación con el caso de Nancy y Marcio, en que los peticionarios no hicieron referencia expresa a los dispositivos que entendían haber sido violados por el estado, la Comisión explicó que

Ni la Convención Americana ni el Reglamento de la $\mathrm{CIDH}$ requiere que el peticionario identifique los derechos especificos que alega haber sido violados por el Estado sobre el tema presentado a la CIDH, aunque los peticionarios puedan hacerlo. Es de competencia de la Comisión Interamericana, basándose en la jurisprudencia del Sistema, determinar en sus informes de admisibilidad los artículos de los instrumentos interamericanos relevantes que son aplicables y, en el final, para establecer si se violó esa disposición y si los hechos alegados fueron comprobados con pruebas suficientes.

Para los otros casos, como puede verse, por unanimidad fueron reconocidas las posibilidades de violación del art. 25 de la Convención, que prevé sobre la Protección Judicial, es decir, reconoce la posibilidad de violación de la ley "[...] a un recurso simple y rápido o a cualquier otro recurso efectivo ante los jueces o tribunales competentes [...] ", asegurando una decisión sobre los derechos ante el Estado brasileño.

Tales violaciones, en los casos concretos analizados, fueron representados por el retraso de las autoridades brasileñas en iniciar o dar seguimiento a las investigaciones para la verificación de las violaciones de derechos perpetradas contra las víctimas, así como por el retraso en la ejecución de las sanciones aplicadas en los casos donde hubo adecuado análisis y juicio del mérito. 


\section{CONSIDERACIONES FINALES}

Desde el final de la segunda guerra mundial, los derechos humanos vienen demostrando una impresionante capacidad para establecer, entre los Estados, parámetros comunes de comportamiento y de conducta por medio de declaraciones y tratados internacionales.

Entre los derechos humanos en general, se destaca la evolución de los derechos humanos de las mujeres, que desde 1975, Año Internacional de la Mujer, se ha incorporado a las normas del derecho internacional público en el marco de los sistemas de protección internacional global y regional, de las cuales son ejemplos: la Convención sobre la eliminación de todas las formas de discriminación contra la mujer/1979 y la Convención Interamericana para Prevenir , Punir y Erradicar la Violencia Contra la Mujer/1994. .

A pesar de la existencia de este fenómeno, la capacidad para implementar esas reglas y principios contra los Estados que las incumplen no ha sido suficiente, y una respuesta eficaz todavía depende prioritariamente de la voluntad política y del ordenamiento interno de cada país. Esto significa que: a las violaciones ocurridas dentro de los Estados, se recurre en primer lugar a sus competencias en la solución de los conflictos.

Por otro lado, la estructura de los sistemas convencionales de monitoreo, basados casi exclusivamente en la figura de los Comités Internacionales, casi no posee poderes judiciales que les permitan sancionar los Estados Partes, responsables por las violaciones de las convenciones. Aunque la Comisión Interamericana de Derechos Humanos puede ofrecer recomendaciones, publicar informes y relatar la situación política y legislativa de cada Estado, el medio más eficaz para hacer cumplir las obligaciones de los tratados, todavía se ciñe a la revisión política, positiva o negativa, expuesta en un foro internacional.

Debido a esto y a los altos niveles de violaciones contra las mujeres por los/en los Estados en general, el Sistema Americano de Derechos Humanos, específicamente la Comisión Interamericana, ha intentado avanzar en la ponderación de los requisitos de admisibilidad de las demandas, adoptando el "criterio de razonabilidad" del plazo como una regla, en relación con la excepción del requisito de "agotamiento de los recursos internos".

En este sentido, la mayor aceptación de las peticiones y de las quejas individuales por la Comisión va a reflejar un compromiso más amplio de los Estados, con referencia a recepciones/adaptaciones legislativas, como en el caso brasileño de reconocimiento de la naturaleza "violencia sexual contra la mujer" en el ámbito doméstico y la adopción de un tipo penal específico: el feminicidio. No de otro modo, las políticas públicas fueron también ampliadas y profundizadas, 
como el aumento en el número de comisarías de policía y juzgados especializados en recibir y decidir sobre las denuncias de violencia contra la mujer.

\section{REFERENCIAS}

AMARAL, M.G.. A sociedade civil brasileira no monitoramento dos direitos humanos: O Relatório Alternativo. Santa Catarina, Florianópolis. 05 de mayo de 2006.

BRASIL. Decreto Legislativo $\mathrm{n}^{\mathrm{o}} 22$ de 26 de mayo de 1992a. Se aprueba el texto de la Convención sobre los Derechos Humanos (Pacto de San José) celebrado en San José de Costa Rica, el 22 de noviembre de 1969, en la Conferencia Especializada Interamericana sobre Derechos Humanos. Brasilia. 1992. Disponible en: $<$ http://legis.senado. gov.br/legislacao/ListaPublicacoes.action?id=136444>. Acc so el: 20 jan. 2017.

BRASIL. Decreto $n^{\circ}$ 678, de 06 de noviembre de 1992 b. Promulga la Convención Americana sobre Derechos Humanos (Pacto de San José de Costa Rica), de 22 de noviembre de 1969. Brasilia. 1992. Disponible en: $<$ http://www.planalto.gov.br/ccivil_03/decreto/D0678.htm $>$. Acceso el: 20 jan. 2017.

COMPARATO, F.K.. A afirmação histórica dos direitos humanos. 3 ed. São Paulo: Saraiva, 2003.

NEGREIROS, M. J. Padrões de Acesso à Justiça do Sistema Interamericano de Proteção dos Direitos Humanos para as Mulheres Vítimas de Violência. Rio de Janeiro - RJ: PUC, Departamento de Derecho, 2010.2. 95p. Disponible en: <http://www.maxwell.lambda. ele.puc-rio.br/16791/16791.PDF>. Acceso el 28 de marzo de 2014.

OEA. CIDH. Publicaciones. Informes anuales. Disponible en:

$<$ http://cidh.oas.org/Publicacoes.htm>. Acceso en: 10 julio. 2015.

OEA. CIDH. Publicaciones. Informes anuales. Disponible en: $<$ http:// www.oas.org/es/cidh/informes/anuales.asp > . Acceso en: 10 julio. 2015.

OEA. CIDH. Publicaciones. Convenção Americana sobre Direitos Humanos. Disponible en: < https:/www.cidh.oas.org/basicos/ portugues/d.Convencao_Americana_Ratif..htm >. Acceso en: $20 \mathrm{de}$ enero de 2017.

PIOVESAN, F. Direitos Humanos e o direito constitucional internacional. São Paulo: Max Limonad, 2000.

TRINDADE, A.A.C. A proteção internacional dos direitos humanos: fundamentos jurídicos e instrumentos básicos. São Paulo: Saraiva, 1991. 